\title{
Popularização da ciência na preparação para as olimpíadas brasileiras de astronomia: uma análise de desempenho
}

Popularization of science in preparation for brazilian astronomy olympics: a performance analysis Popularización de la ciencia en preparación para los juegos olímpicos de astronomía brasileña: un análisis del desempeño

Jeane Auxiliadora da Silva

ORCID: https://orcid.org/0000-0002-1840-771X Universidade Federal de Itajubá, Brasil

E-mail: jeanesilva@unifei.edu.br

Mateus Ferreira Belício

ORCID: https://orcid.org/0000-0002-3494-6860 Universidade Federal de Itajubá, Brasil

E-mail: mateusbelicio@unifei.edu.br

Bárbara Kimberly Moraes

ORCID: https://orcid.org/0000-0001-7050-2645 Universidade Federal de Itajubá, Brasil E-mail barbarakimoraes@hotmail.com

Maria Luiza Souza Caetano

ORCID: https://orcid.org/0000-0003-1138-767X Universidade Federal de Itajubá, Brasil

E-mail: mlcaetano34@gmail.com

Lourival Fernandes Nogueira Neto

ORCID: https://orcid.org/0000-0002-9390-250X Universidade Federal de Itajubá, Brasil

E-mail: lourivalneto@unifei.edu.br

Maria Kleire Mendes Rodrigues ORCID: https://orcid.org/0000-0001-5883-6765 Colégio Municipal Professora Didi Andrade, Brasil E-mail: mariakleire@yahoo.com.br Renata dos Santos

ORCID: https://orcid.org/0000-0002-6731-1255 Universidade Federal de Itajubá, Brasil E-mail renatasantos@unifei.edu.br

Márcio Tsuyoshi Yasuda

ORCID: https://orcid.org/0000-0002-5532-4403 Universidade Federal de Itajubá, Brasil E-mail: marcioya@unifei.edu.br

Evandro Augusto de Morais

ORCID: https://orcid.org/0000-0001-9927-7656 Universidade Federal de Itajubá, Brasil

E-mail: evmorais@unifei.edu.br

Edelma Eleto da Silva

ORCID: https://orcid.org/0000-0002-1498-9134 Universidade Federal de Itajubá, Brasil E-mail: edelmasilva@unifei.edu.br

\begin{abstract}
Resumo
A Olimpíada Brasileira de Astronomia e Astronáutica (OBA) teve sua primeira edição em 1998, promovendo, no Brasil, um evento educacional, com foco científico, já consolidado internacionalmente. O Grupo do Programa de Educação Tutorial de Conexões de Saberes em Física e Popularização da Ciência da Unifei (Campus Avançado de Itabira) criou um programa de atendimento e preparação de alunos com oficinas e gincanas de Astronomia. m parceria com um colégio de Ensino Fundamental de Itabira (MG). Baseado em uma metodologia que busca aliar o prazer em aprender com estudo constante dos alunos nos temas propostos, este programa visa solucionar as dificuldades no processo de formação dos alunos, na assimilação e construção de conhecimentos científicos e no processo de ensinoaprendizagem. Assim, diversas reações importantes foram observadas e este trabalho tem como objetivo mostrar análises relacionadas ao desempenho dos alunos do colégio na OBA. Foi verificado aumento de notas médias das turmas do $7^{\circ}$ ao $9^{\circ}$ ano, destacando-se as turmas do $7^{\circ}$ ano com aumento de rendimento de $36 \%$. Consequentemente, houve um aumento significativo no número de medalhas conquistadas, passando de 1 medalha para cada 50 alunos em 2015 para aproximadamente 1 medalha para cada 4 participantes em 2019.
\end{abstract}


Palavras-chave: Astronomia; Olimpíada; Popularização da ciência.

\begin{abstract}
The Brazilian Astronomy Olympics and Astronautics (OBA) had its first edition in 1998, promoting in Brazil an educational event, with a scientific focus, already consolidated internationally. The Group of the Tutorial Education Program of Knowledge "Conexão de Saberes em Física e Popularização da Ciência” at Unifei ("Campus Avançado de Itabira") created a students assistance and preparation program with workshops and gymkhanas on Astronomy. Based on a methodology to add the pleasure of learning with the constant study of the students in proposed themes, this program aims to solve the difficulties in the process of student training, in the assimilation and construction of scientific knowledge and in the teaching-learning process. Based on this program, several important reactions were observed and this work aims to show analysis related to the performance of its participants at OBA. An increase in average grades was verified among the students from the 7th to 9th grades, especially the seventh graders, who performed $36 \%$ better. Consequently, there was an expressive increase in the number of won medals, from 1 medal for 50 participants in 2015 to 1 medal for 4 participants in 2019.
\end{abstract}

Keywords: Astronomy; Olympics; Popularization of science.

\title{
Resumen
}

La Olimpiada Brasileña de Astronomía y Astronáutica (OBA) tuvo su primera edición en 1998, promoviendo en Brasil un evento educativo, con enfoque científico, ya consolidado internacionalmente. El Grupo del Programa de Educación Tutorial de Conexión del Conocimiento "Conexão de Saberes em Física e Popularização da Ciência" de la Unifei (Campus Avanzado de Itabira) creó un programa de asistencia y preparación a los estudiantes con talleres y gymkanas sobre Astronomía. Basado en una metodología para sumar el placer de aprender con el estudio constante de los estudiantes en los temas propuestos, este programa tiene como objetivo resolver las dificultades en el proceso de formación de los estudiantes, en la asimilación y construcción del conocimiento científico y en el proceso de enseñanza-aprendizaje. Con base en este programa, se observaron varias reacciones importantes y este trabajo tiene como objetivo mostrar un análisis relacionado con el desempeño de sus participantes en OBA. Se verificó un aumento en las calificaciones promedio entre los estudiantes de $7^{\circ}$ a $9^{\circ}$ grado, especialmente los de séptimo grado, quienes obtuvieron un $36 \%$ mejor. En consecuencia, hubo un aumento significativo en el número de medallas ganadas, de 1 medalla para 50 participantes en 2015 a 1 medalla para 4 participantes en 2019.

Palabras clave: Astronomía; Juegos olímpicos; Popularización de la ciencia.

\section{Introdução}

O interesse do homem pela observação dos astros existe desde os tempos pré-históricos, por isso a Astronomia é considerada uma das mais antigas ciências. Os mais antigos registros datam de aproximadamente 3.000 a.C., para os quais chineses, assírios, babilônios e egípcios foram fundamentais nos estudos dessa ciência milenar. Naquela época, os astros já eram usados para medir a passagem do tempo, dando origem aos calendários e auxiliando os povos a identificarem a melhor época para o plantio e para a colheita. Eles também eram empregados como referência para sistemas de navegação, método ainda utilizado nos dias de hoje (Oliveira Filho \& Saraiva, 2013).

No início do século XX, parte considerável das informações relacionadas à astrologia era de cunho religioso, místico ou tratava do movimento dos corpos celestes (Celletti \& Perozzi, 2007). Só a partir desse período, a observação do céu permitiu responder questões relacionadas à origem da Terra e do Universo (Bertolami, 2016) e a Cosmogonia se desenvolveu, assim como a Filosofia passou a influenciar na forma de olhar o espaço e vários elementos que o compõem. Diante disso, a estreita relação entre Ciência e Filosofia passa a ser percebida durante o período conhecido como revolução científica, que teve seu início simbólico quando Galileu Galilei fez uso do telescópio para observar a Lua (Costa Junior et al., 2018), proporcionando assim avanços no estudo da Astronomia.

Inúmeras descobertas científicas vêm sendo alcançadas recentemente e comprovando resultados teóricos previstos do século passado, como exemplo a comprovação da existência de ondas gravitacionais em 2016 (Ramos \& Maluf, 2018), a qual teve enorme repercussão, inclusive rendendo prêmio Nobel de Física aos pesquisadores em 2017 (Bassalo \& Cattani, 2018). Tais avanços somente são possíveis devido ao constante desenvolvimento experimental, desde a evolução da Física óptica, com a construção de telescópios e observatórios, até o lançamento de telescópio no espaço e controle de imagens, como o 
telescópio Hubble em 1990 (Schwarza, 2018). Assim, junto com a evolução dos estudos sobre a Astronomia no meio científico veio a sua popularização, promovida por diversos cientistas e meios de comunicação. Talvez, o maior divulgador na história tenha sido o cientista Carl Sagan (Schwarza, 2018), com sua vasta produção bibliográfica, autor de inúmeros livros, artigos e da premiada série “Cosmos, Uma viagem pessoal” (Sagan, 1980; Sagan \& Druyan, 1980).

No Brasil, os conteúdos relacionados a Astronomia fazem parte da ementa a ser ensinada em escolas. Desde a década de 1990, com as reformas da educação formal, os Parâmetros Curriculares Nacionais (PCNs) passaram a sugerir que alguns assuntos de Astronomia fossem ensinados no Ensino Fundamental e no Ensino Médio, fornecendo as diretrizes para a elaboração dos currículos com vistas principalmente à formação para a cidadania. Na atualidade, com a aprovação da Base Nacional Comum Curricular (BNCC), que normatizou, em nível nacional, as aprendizagens essenciais a que todo aluno da Educação Básica deve ter acesso, o estudo da Astronomia estará presente desde os anos iniciais. No Ensino Fundamental, assuntos acerca da Astronomia são abordados nas disciplinas de Geografia e Ciências, enquanto que, no Ensino Médio, na disciplina da Física (Costa Junior et al., 2018). O ensino de Astronomia durante a Educação Básica está fortemente amparado pela BNCC, uma vez que os novos conteúdos das ciências estão organizados de forma a assegurar o acesso do aluno à diversidade dos conhecimentos científicos e aos principais processos, procedimentos e práticas de investigação científica. A inserção do tema, no processo de formação continuada dos alunos, no entanto, torna-se preocupante, uma vez que os professores necessitam de formação ou capacitação adequada para abordarem o tema em sala de aula (Leite \& Hosoume, 2007). Isso gera risco de conceitos fundamentais deixarem de ser explorados com os alunos em sala de aula ou de serem apresentados de forma equivocada.

A falta de capacitação apropriada de muitos professores em lecionar o conteúdo de Astronomia tem sua origem, em muitos casos, em seus processos de formação no Ensino Superior. Desde a criação do primeiro curso de Astronomia em 1958, na antiga Universidade do Brasil, muitas transformações ocorreram chegando ao ponto de seus conteúdos serem somente oferecidos como disciplinas optativas (Langhi \& Nardi, 2009). Além disso, na maioria das vezes, os docentes se veem obrigados a ministrar aulas de conteúdos para os quais não estão plenamente qualificados e, somado a isso, existem livros didáticos com conceitos explicados de forma errônea (Canalle, Trevisan, \& Lattari, 1997; Langhi \& Nardi, 2007). Acredita-se que um fator agravante para a capacitação dos docentes no município de Itabira (Minas Gerais), onde o projeto foi aplicado, baseia-se na cultura extrativista, em que a empresa mineradora instalou vilas com escolas, farmácias e lojas (L. N. M. Souza, 2019). Apesar de isso ser um facilitador por sanar a necessidade de seus empregados, em relação à infraestrutura da cidade, criaram-se limitações de vínculos e vivências com o município e laços de dependências com ela. E do comportamento proveniente desses fatos iniciais e da real finalidade dos setores extrativistas surge o questionamento sobre a possibilidade de atender às necessidades locais e regionais prioritariamente às globais (L. N. M. Souza, 2019).

Uma parceria entre Prefeitura Municipal de Itabira, empresa Vale, Ministério da Educação (MEC) e Universidade Federal de Itajubá (Unifei) gerou a implantação do Campus Avançado de Itabira em 2008. Cada parceiro teve um papel bem definido e fundamental para o funcionamento da Universidade: a Prefeitura de Itabira construiria o campus da universidade (infraestrutura), a montagem dos laboratórios (aquisição de equipamentos de ensino) ficaria por conta da Vale, e a Unifei seria responsável pelos recursos humanos, atividades de formação, geração e aplicação de conhecimento ("Unifei/História," 2018). Hoje, a Unifei opera em instalações provisórias, mas desempenha seu papel fundamental sobre um pilar baseado no ensino, pesquisa e extensão para a formação de Engenheiros.

As dificuldades anteriormente citadas mostram que o ensino de Astronomia é um desafio a ser superado, visando à inserção do aluno no âmbito da criatividade, curiosidade e da participação, tornando-o protagonista de seu próprio conhecimento (Langhi \& Nardi, 2005; Rodrigues \& Briccia, 2016). No ambiente escolar, o ensino ocorre com estrutura e planejamento próprios, de forma didática e obrigatória por lei. Entretanto, o ensino da Astronomia em si nem sempre é inserido 
nesse contexto de obrigatoriedade, sendo muitas vezes deixado de ser aplicado, tanto no Ensino Fundamental quanto no Ensino Médio (Marandino et al., 2004).

Muitos termos conceituais surgem para definir os processos de ensino-aprendizagem, os quais podem ocorrer em diversos domínios definidos como educação formal, informal e não formal (Langhi \& Nardi, 2009). Suas definições levam em conta tanto o ambiente em que se dá o processo de ensino-aprendizagem, quanto o planejamento ou não dos conteúdos e metodologia usada. Na realidade, tais definições são complexas, com uma linha tênue entre cada processo de ensinoaprendizagem. Diversas atividades são desenvolvidas para a construção do conhecimento científico, seja para alunos, nas escolas em diversos níveis da educação formal, seja para a população em geral. Um termo muito comum, usado quando se pensa em ensino científico no sentido do meio acadêmico para o povo, é a popularização da ciência, o qual se confunde historicamente com outros termos como vulgarização, difusão e alfabetização científica (Germano \& Kulesza, 2007). Assim, o conceito de popularização deixa de ser considerado apenas a transposição do conhecimento científico para indivíduos que não estão inseridos na academia para, em um sentido mais amplo e bem-aceito, considerar: a compreensão do mundo em que vive, as condições para formular opiniões a partir de reflexões e condições de debater, possibilitando assim uma ação cultural libertadora (Germano \& Kulesza, 2007).

Conforme descrito, o ensino pode acontecer por meio de diferentes métodos e alguns deles também se dão por jogos e brincadeiras, que são vistos como os métodos lúdicos de ensino (Miranda, Gonzaga, Costa, Freitas, \& Côrtes, 2016; Paula \& Sanzovo, 2018) e promovem o desenvolvimento pessoal, cultural e social, facilitando os mais variados processos de expressão, socialização, comunicação e construção do conhecimento (Arantes \& Barbosa, 2017). Outros estudos, anteriores a primeira Olimpíada Brasileira de Astronomia e Astronáutica (OBA), mostram diferentes abordagens baseadas em hábitos de observação da natureza e de formulação de perguntas que conduzem os alunos à "atitude científica" (Neves, 1986).

Olimpíadas são consideradas uma fonte importante de divulgação científica e a OBA, evento educacional de nível nacional, foi criada para divulgar a Astronomia no Brasil, promovendo o interesse de professores no tema "Astronomia" (Erthal \& Vieira, 2019). Corroborando tal aspecto de importância, Lavouras (1998, p. 1) expôs que

A ideia de realizar uma Olimpíada de Astronomia nasceu da conjunção do interesse pelo desenvolvimento da ciência, com a oportunidade de trazer para o Brasil um evento científico educacional, consolidado internacionalmente. O potencial de uma Olimpíada de Astronomia vai até onde nossa ousadia puder imaginar (Lavouras, 1998, p. 1).

Através da abordagem adotada de forma pioneira na região de Itabira (MG), o grupo vinculado ao Programa de Educação Tutorial (PET)/"Conexões de Saberes em Física e Popularização da Ciência" (PETFIS), da Universidade Federal de Itajubá (Unifei) - Campus de Itabira, desenvolveu o projeto intitulado "O Ensino de Astronomia na Educação Básica". Com o objetivo de sanar parte da defasagem em conceitos básicos sobre a Astronomia, durante o Ensino Fundamental, foram usados métodos lúdicos de ensino, os quais foram aplicados durante as oficinas, e linguagem simples adaptada aos alunos do $6^{\circ}$ ano do Colégio Municipal Professora Didi Andrade, para estimular a criatividade, a comunicação e consequentemente maior interesse dos alunos pelo tema. Por um lado, este trabalho é uma forma de divulgar e popularizar a Ciência, partindo do princípio que estudantes e professores recebem conteúdos atualizados sobre o tema (Canalle et al., 2010). Por outro lado, uma análise crítica traça um paralelo com a competição, como exemplo a prática esportiva, em que o sucesso de um atleta demanda enorme preparo, condições favoráveis e consome praticamente todo seu tempo. Assim, a competição, no caso das olimpíadas escolares, levaria a uma clara exposição das diferenças sociais das escolas participantes e até mesmo entre alunos em uma mesma escola e levaria à formação de dois grupos distintos, os vencedores e os perdedores (Rezende \& Ostermann, 2012). A competição não elimina as desigualdades escolares e essas são atreladas às desigualdades sociais (Dubet, 2004). Uma das alternativas para as escolas seria corrigir as desigualdades com treinamento, fazendo uso de estudos dirigidos e demais práticas 
que visem à preparação (Dubet, 2004). Outros trabalhos da literatura fazem uso de intervenções via oficinas como importante mecanismo de assimilação conceitual dos alunos (Felicetti, Miorando, \& Ohse, 2017).

Na próxima seção será apresentada a metodologia aplicada pelo PETFIS e posteriormente uma análise do desempenho na OBA dos alunos do $6^{\circ}$ ao $9^{\circ}$ ano do Colégio Municipal Professora Didi Andrade após o trabalho realizado pelo grupo PETFIS e professora de Ciências. A partir das notas obtidas pelos alunos na OBA, bem como suas premiações na forma de medalhas nas modalidades ouro, prata e bronze, as análises pretendem mostrar a qualidade da metodologia usada para o compartilhamento e construção de conceitos relacionados a Astronomia.

\section{Metodologia}

De acordo com o método científico (Pereira, Shitsuka, Parreira, \& Shitsuka, 2018), este trabalho traz uma análise quantitativa do desempenho a partir de medalhas conquistadas e notas dos alunos do Colégio Municipal Professora Didi Andrade que participaram da OBA entre 2014 e 2019, um total de 198 alunos. Foi avaliada a eficiência da metodologia de estudos - elaborada em parceira com a professora de Ciências da escola - proposta aos alunos. Além disso, são considerados relatos da professora de Ciências e dos integrantes do grupo PETFIS. As atividades do projeto foram desenvolvidas de maneira lúdica e interativa e com uso de linguagem simples e apropriada à faixa etária dos alunos, o que propiciou sua participação ativa e os motivou a se esforçar, criar, refletir e socializar com os demais colegas participantes do projeto. Afinal, o projeto Ensino de Astronomia na Educação Básica desenvolvido pelo grupo PETFIS partiu de argumentações como: Quem nunca parou por um momento para olhar fixo para uma estrela e contemplar seu brilho? Parou para observar a Lua e suas diferentes formas ou contemplou uma noite sem nuvens para ver o céu? Indagou se aquele pontinho brilhante seria um planeta? Enfim, o que está contido no Universo? Quem nunca quis entender um eclipse? O que é, na verdade, uma "estrela cadente"? Quem nunca correu em direção a sua televisão para ver uma notícia relacionada a Astronomia? Quem nunca quis apontar uma luneta para o céu? Quem nunca se confundiu, achando que um satélite era algum disco voador? Vale lembrar que aqueles que já tiveram o privilégio de ir a um planetário certamente se lembram da sensação incrível. Aqui foram citadas apenas algumas situações relacionadas ao olhar para o céu. Podem ainda ser considerados os efeitos da Lua nas marés, a inclinação do eixo da Terra e o clima, entre outras inúmeras situações.

Convém considerar que quase todos já se flagraram fazendo isso ou ainda vão fazê-lo em algum momento da vida, e que a partir desse ponto começam a aparecer muitos questionamentos, sem, na maioria das vezes, terem respostas precisas. Assim, diante de tantas dúvidas, são iniciadas as discussões e oficinas, nas quais a difusão de questões para a compreensão da Ciência domina o ambiente.

Durante o período de 2014 a 2019, o Grupo PETFIS ministrou oficinas para todas as turmas do $6^{\circ}$ no Colégio Municipal Professora Didi Andrade oferecendo as oficinas intituladas "Dia e Noite", "Constelações", "Ordem dos Planetas no Sistema Solar e seus Tamanhos" e uma gincana de encerramento. As atividades ocorreram mensalmente no segundo semestre de cada ano, com atuação do PETFIS de forma quinzenal e com a atuação da professora de forma semanal, sob a supervisão da professora de Ciências do referido Colégio. As oficinas, com duração média de 50 minutos, foram realizadas com todos os alunos das turmas do $6^{\circ}$ ano com periodicidade quinzenal. Durante a oficina, todos os alunos receberam um kit para desenvolver suas atividades e contaram com o auxílio dos monitores.

A oficina "Dia e Noite" foi promovida para explicar os movimentos de rotação e translação da Terra e para isso foram utilizados: cartolina, imagem de um planisfério para colorir, palito de churrasco, esfera de isopor de $10 \mathrm{~cm}$, pedaço de lã, canudinho, palito de dente, cola, tesoura e compasso. A oficina foi realizada com base na construção da maquete baseada na proposta de Pliessing (2008), tendo como diferencial a colagem de um planisfério com as delimitações dos continentes para os alunos colorirem. 
Para essa maquete, foi recortado um pedaço de $20 \times 25 \mathrm{~cm}$ de cartolina, logo em seguida dobrado ao meio e então foi feito um círculo de $11 \mathrm{~cm}$ de diâmetro em seu centro com o auxílio do compasso. O palito de churrasco foi espetado na bola de isopor, atravessando-a e deixando apenas $3 \mathrm{~cm}$ do palito para fora. Antes dessa etapa, os alunos coloriram, recortaram e colaram o planisfério na esfera. Os canudos foram utilizados para cobrir as pontas do palito que estavam expostas. Cada extremidade do palito foi colada de um lado da cartolina e o conjunto foi apoiado sobre um pedaço retangular de cartolina que foi colocada como suporte para dar equilíbrio e fazê-lo ficar de pé. O pedaço de lã foi utilizado para reproduzir a linha do Equador na bola de isopor.

A oficina "Constelações" foi realizada com o objetivo de demonstrar aos alunos a utilidade das constelações na antiguidade e nos dias atuais, além de ensiná-las a se localizarem com a ajuda de um planisfério, criado por elas mesmas. Para sua execução, foram utilizados: figuras de um planisfério, tachinha, pedaço de placa emborrachada de Etil, Vinil e Acetato (EVA), tesoura e bússola.

Durante o processo, destacou-se que o planisfério é composto por duas partes: a primeira com a carta celeste (estrelas impressas no centro, e na sua borda os 365 dias do ano) e a segunda com a máscara do horizonte (divisão horária impressa em sua borda, e horizonte de acordo com a latitude do lugar onde será utilizado). Essas duas partes foram fixadas pelo centro em uma base com uma tachinha, que representa o polo celeste Sul. O EVA foi utilizado para a proteção da ponta da tachinha, de forma que os alunos não se machucassem. Com esse conjunto construído, foi possível alinhar o horário e data, ambos dispostos no planisfério construído, referentes ao momento que se gostaria de fazer a análise das posições das constelações que estariam visíveis. A bússola foi usada para localizar a direção do Norte e, dessa forma, identificar os outros pontos cardeais.

A oficina "Ordem dos Planetas no Sistema Solar e seus Tamanhos" foi realizada com o objetivo de apresentar aos alunos os planetas que compõem o Sistema Solar, com suas trajetórias, ordem de proximidade do Sol e características geológicas, como tamanho. Para a execução do experimento, foram utilizados: desenhos dos planetas para colorir, cartolina branca, papel sulfite amarelo, cola, tesoura e giz de cera de cores variadas.

Inicialmente foi necessário pintar as figuras dos planetas, de forma a tentar deixar as cores mais parecidas com as cores originais, antes de recortá-los com a tesoura. O papel sulfite amarelo, utilizado para simbolizar o Sol, foi colado na extremidade da cartolina e, em seguida, foram colados os planetas, sempre respeitando a ordem que estão dispostos no Sistema Solar. Vale ressaltar que foi abordado com os estudantes o caráter representativo das maquetes construídas por eles, explicitando que as relações entre os tamanhos dos planetas, assim como as distâncias em relação ao Sol, não poderiam ser representadas de forma mais próximas do real, mesmo utilizando escalas menores, devido às suas relações de tamanho e distância serem muito desproporcionais. Por exemplo, Júpiter é aproximadamente 29 vezes maior que Mercúrio e Netuno e está a uma distância média do Sol de aproximadamente 75 vezes maior que está Mercúrio do Sol.

Como atividade final, foi realizada uma gincana com todos os assuntos abordados e com premiação para os alunos de maior destaque durante o projeto. Além disso, foram realizadas apresentações de filmes de diversos assuntos relacionados ao sistema solar, em um planetário móvel.

É importante mencionar que as oficinas foram realizadas, exclusivamente, para os alunos do $6^{\circ}$ ano, no Colégio Municipal Professora Didi Andrade, no segundo semestre dos anos de 2014 a 2019, em colaboração com a professora de Ciências dessa escola. Desse modo, a participação do PETFIS auxiliou o preparo dos alunos para a OBA de forma bem efetiva. A preparação dos alunos ocorreu sempre no ano anterior a sua participação na OBA. Sendo assim, os alunos que participaram das oficinas no segundo semestre de 2014 participaram da OBA em 2015, aproximadamente seis meses depois, e a maioria deles já estava no $7^{\circ}$ ano. 


\section{Resultados e Discussão}

Com os conhecimentos adquiridos pelos discentes nas aulas de Ciências e nas atividades propostas durante as oficinas, realizadas pelo Grupo PETFIS, muitos alunos do Colégio Municipal participaram da OBA. Foram coletados dados referentes às notas obtidas nas avaliações e premiação destes alunos, os quais foram analisados para verificar o aproveitamento destes alunos na OBA e o papel do grupo no desenvolvimento do saber.

Com a introdução das atividades, os alunos foram motivados a pensar sobre as formas e dimensões dos astros, como funciona o sistema solar e refletir sobre o Universo ao qual os seres humanos estão imersos e que constantemente o transformam para que suas necessidades possam ser atendidas.

Na OBA, as provas são divididas em dois temas, a Astronomia e a Astronáutica, ocorrem desde 1998 e estão divididas em quatro níveis, os quais se definem por nível de escolaridade. Os alunos, objeto deste estudo, encontram-se no nível 3 destinado aos alunos do $6^{\circ}$ ao $9^{\circ}$ ano.

Durante o período de 2014 a 2019, os discentes do Colégio Municipal Professora Didi Andrade participaram da olimpíada de forma não obrigatória e, em cada ano, um número diferente de discentes participou da competição. Para que se tenha uma análise fiel da realidade, é apresentada, como primeira comparação, a relação entre participantes e medalhistas da escola. A Tabela 1 ilustra o crescimento do número de medalhistas, apesar do número decrescente de participantes. Possivelmente este fato se deu pelo desenvolvimento do projeto de forma efetiva.

Tabela 1: Relação entre número de participantes e medalhistas na OBA no período de 2014 a 2019.

\begin{tabular}{ccc}
\hline Ano da OBA & Participantes & Número de medalhas \\
\hline 2014 & 33 & 0 \\
2015 & 51 & 1 \\
2016 & 34 & 3 \\
2017 & 29 & 6 \\
2018 & 28 & 8 \\
2019 & 23 & 6 \\
\hline
\end{tabular}

Fonte: Dados compilados dos arquivos do Colégio Municipal Professora Didi Andrade.

Percebe-se que, neste período, houve o aumento do número de medalhas recebidas pelos alunos em todas as categorias de premiação (ouro, prata e bronze). A Figura 1a apresenta as distribuições de medalhas de bronze, prata e ouro conquistadas pelos alunos da escola. Na Figura 1b, é possível observar a média das notas de cada ano do Ensino Fundamental, no período de 2014 a 2019. 
Figura 1: a) Medalhas obtidas na OBA no período de 2014-2019 e b) Média das notas em cada ano durante o período de 2014 a 2019

(a)

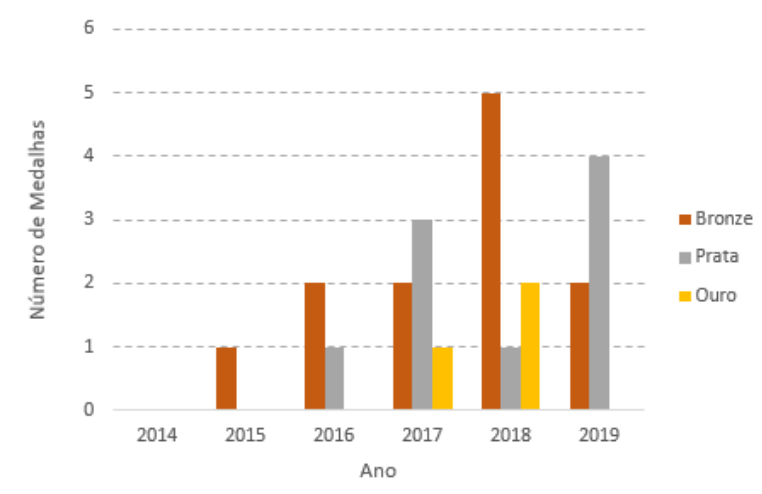

(b)

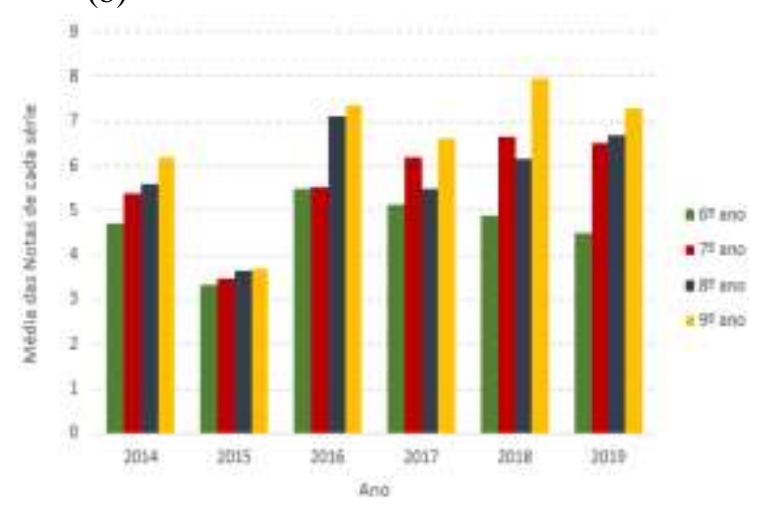

Fonte: Autores.

Fica evidente a evolução do número de medalhas alcançadas, após o trabalho do grupo PETFIS e docentes da escola. Além disso, o trabalho passa a ser agraciado com a premiação dos alunos com medalhas nas modalidades: prata, a partir de 2016; e ouro, a partir de 2017. Isso deixa clara uma significativa melhora no desempenho dos alunos. Sem hesitar, pode-se afirmar que a Olimpíada é um meio extremamente eficaz para motivar os estudantes, o que corrobora o discurso oficial da OBA, que busca levar aos estudantes e professores conteúdos corretos e atualizados relacionados a Astronomia (Erthal \& Vieira, 2019). Apesar dos problemas de divisão entre vencedores e perdedores em práticas competitivas, quando a metodologia busca um equilíbrio entre competição e colaboração (Rezende \& Ostermann, 2012), efeitos benéficos para os processos de ensino e aprendizagem são perceptíveis. Neste trabalho, tais ações foram realizadas através da parceria do grupo PETFIS com a professora de Ciências, levando em conta as necessidades dos alunos, tendo em vista a percepção sobre a preparação de Dubet (2004) para minimizar o efeito da desigualdade escolar. Considerando as notas das avaliações, fica evidente a melhora de desempenho dos alunos, o que pressupõe que o trabalho realizado respeitou a necessidade dos alunos por meio de uma prática pedagógica apropriada.

É perceptível uma sutil melhora dos estudantes do Colégio que participaram das olimpíadas. A exceção se deu em 2015, mesmo tendo um número superior de participantes (Tabela 1), em que a nota foi inferior ao ano anterior. Isso se deve, provavelmente, ao nível de dificuldade das avaliações aplicadas durante a OBA do referido ano (Canalle et al., 2015). Foi verificado que a nota média brasileira nas avaliações da OBA foi inferior à dos anos anteriores nas avaliações. Apesar desse fato, a escola ainda conseguiu conquistar uma medalha de bronze em 2015 (Figura 1a).

Nos anos subsequentes, foi possível perceber a melhora no desempenho dos alunos na OBA para todos os anos. Essa melhora fica mais evidente quando são observadas as notas dos alunos do $7^{\circ}$ ano (Figura 2 e Tabela 2). Convém lembrar que as oficinas foram oferecidas aos alunos que, no momento da olimpíada, eram cursistas do $7^{\circ}$ ano. A intervenção do grupo PETFIS contribuiu positivamente para a preparação e construção de conhecimento desses alunos, observado pelo desempenho dos alunos nas olimpíadas. Além disso, nos anos consecutivos, $8^{\circ}$ e $9^{\circ}$ ano, esse aprendizado permanece, mesmo que indiretamente, de forma a incentivá-los a continuar participando das olimpíadas seguintes. 
Figura 2: Variação de notas durante o período de 2014 a 2019, com suas respectivas regressões lineares, para os temas: (a) Astronomia, (b) Astronáutica
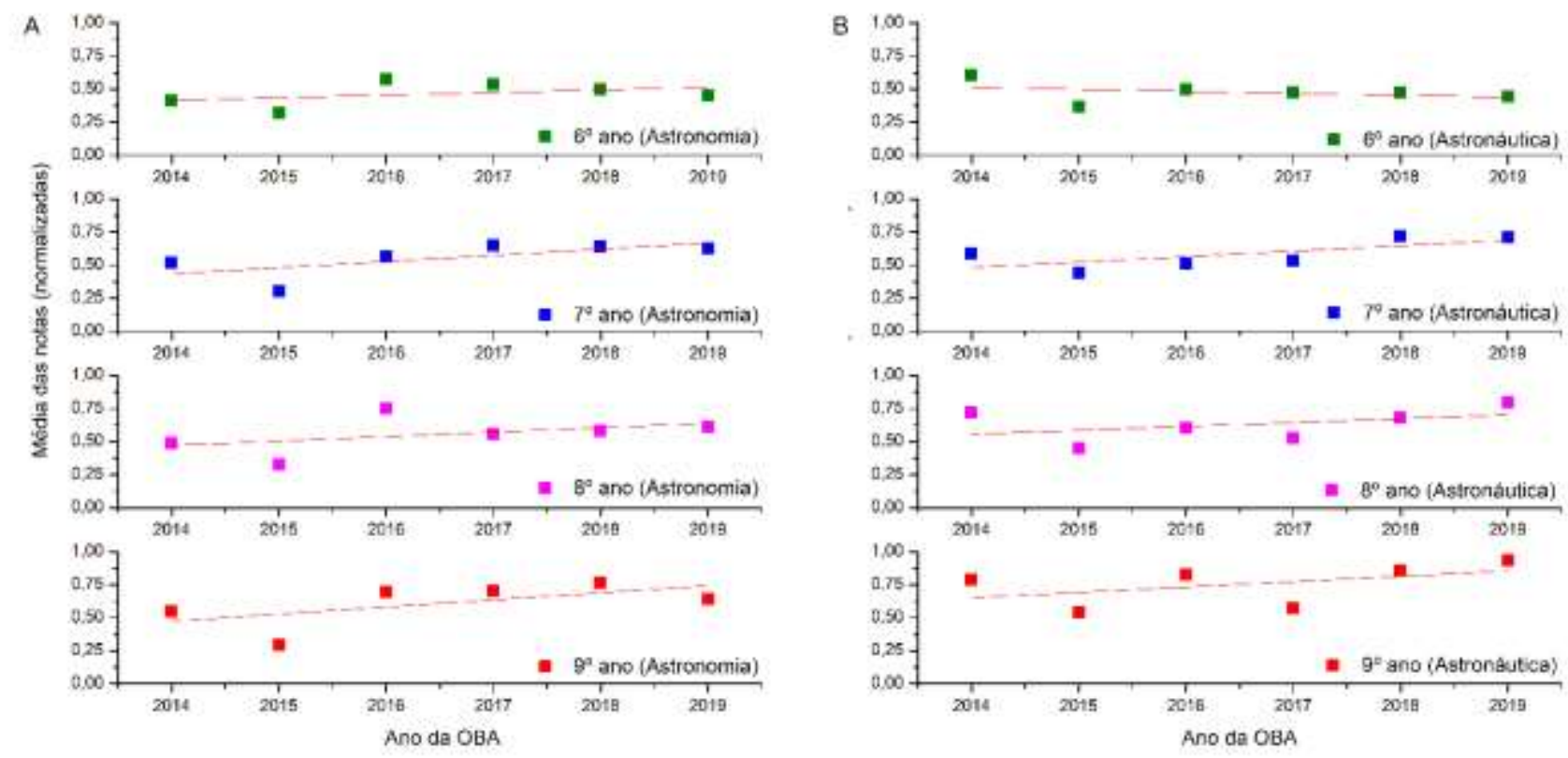

Fonte: Autores.

Uma análise mais detalhada dos dados pode ser feita comparando de forma separada as notas obtidas em temas ligados a Astronomia e a Astronáutica, conforme Figura $2 \mathrm{a}$ e Figura 2b, respectivamente. Na OBA, as notas de cada participante são totalizadas através de uma média ponderada obtida utilizando suas notas em Astronomia com peso 7 e Astronáutica com peso 3. A média das notas dos alunos, normalizadas para cada tema, foi utilizada como parâmetro de evolução e foi observada sua variação temporal. Na normalização, considerou-se que 1 (um) era a maior nota possível para cada uma das avaliações e 0 (zero) a menor, em todas as edições da OBA. O percentual de variação das notas foi calculado em duas etapas. Na primeira etapa, foi utilizada a regressão linear de cada curva por meio de uma equação de primeira ordem do tipo $\mathrm{Y}=\mathrm{a}+\mathrm{bX}$. Uma curva de normalização foi criada para que se encontrasse a maior evolução possível das notas, com aumento de 100\%. Fazendo a regressão linear da curva de normalização, foi identificada a inclinação máxima da reta (coeficiente angular igual a 0,20). As regressões lineares foram traçadas em vermelho e podem ser visualizadas nas Figuras $2 \mathrm{a}$ e $2 \mathrm{~b}$. Pela simples observação da inclinação desses traços, verifica-se uma tendência de crescimento das notas para a maioria das curvas, as quais representam a evolução das médias das notas dos alunos com mesmo grau de instrução. A exceção se dá pelas turmas do $6^{\circ}$ ano, que participaram do OBA antes de participar das oficinas oferecidas pelo PETFIS. Na segunda etapa, para quantizar a evolução do desempenho, foi calculada a proporção entre a inclinação da curva normalizada e o coeficiente angular para cada ano, conforme descrito na primeira etapa. Os resultados da variação percentual de notas estão dispostos na Tabela 2.

O percentual positivo de variação de notas observado é maior para os temas abordados nas oficinas (Astronomia) do que para aqueles que não foram trabalhados diretamente (Astronáutica) para o período de 2014-2019. Na Astronomia, houve um aumento da nota média para todos os anos, com maiores índices no $7^{\circ}$ e $9^{\circ}$ anos, enquanto que para a Astronáutica a variação foi negativa para o $6^{\circ}$ ano, e positiva para os demais. Isso pode parecer estranho, no entanto o $6^{\circ}$ ano não passou pelas oficinas ministradas pelo PETFIS antes de fazer a avaliação na OBA. Tal dado dá indícios de que a intervenção do PETFIS na escola favoreceu o aprendizado dos alunos do Ensino Fundamental na área de Astronomia. Esta informação pode ser reforçada 
quando é utilizada a mesma metodologia para analisar as notas médias dos alunos do $7^{\circ}$ ano, que participaram das oficinas, cujo desempenho aumentou em torno de $36 \%$, enquanto as demais turmas que não participaram das oficinas permaneceram sem alterações significativas do rendimento. $\mathrm{O}$ alto rendimento da turma do $7^{\circ}$ ano também pode ser atribuída pela proximidade temporal entre a participação da oficina e desenvolvimento da prova das olimpíadas.

Tabela 2: Aumento da nota média considerando o período de 2014-2019.

\begin{tabular}{ccccc}
\hline & & Período 2014-2019 & $\begin{array}{c}\text { Turmas } \\
\text { participantes }\end{array}$ \\
\hline Ano & $\begin{array}{c}\text { Astronomia } \\
(\%)\end{array}$ & $\begin{array}{c}\text { Astronáutica } \\
(\%)\end{array}$ & $\begin{array}{c}\text { Total } \\
(\%)\end{array}$ & PET/OBA \\
\hline $6^{\circ}$ & 10 & -7 & 5 & $0 / 6$ \\
$7^{\circ}$ & 23 & 21 & 23 & $5 / 6$ \\
$8^{\circ}$ & 17 & 15 & 16 & $4 / 6$ \\
$9^{\circ}$ & 27 & 20 & 25 & $3 / 6$ \\
\hline
\end{tabular}

Fonte: Dados compilados de arquivos do Colégio Municipal Professora Didi Andrade

A Tabela 2 mostra o aumento da nota média atingida pelos alunos em relação aos conteúdos de Astronomia e Astronáutica. Nesta análise, foram considerados todos os alunos que participaram da OBA, independente da participação nas oficinas do PETFIS. A última coluna indica o número de turmas que participaram das atividades PETFIS e da olimpíada, o que ocorreu a partir do $7^{\circ}$ ano. Observam-se maiores notas para os alunos após atuação do grupo PETFIS na escola, tanto em conteúdos de Astronomia quanto de Astronáutica, bem como na nota geral (Figura 3). No $7^{\circ}$ ano, os alunos tiveram a atuação temporal do grupo PETFIS mais próxima à data da realização da OBA. Observa-se um aumento de $5 \%$ para $23 \%$ ao comparar a nota total do $7^{\circ}$ ano com a do $6^{\circ}$ ano, o qual não participou de oficinas com o grupo (Tabela 2). Desempenhos significativos em ensino foram alcançados por meio da atuação do grupo na comunidade itabirana, com destaque para o aumento na taxa de matriculados na Unifei de participantes do "Curso Preparatório para o ENEM" (Morais et al., 2020) e número de medalhas conquistadas no ano de 2020 na OBA através de ensino virtual desenvolvido pelo grupo (M. A. B. de Souza et al., 2021). Quando separados os grupos de alunos que participaram e que não participaram das oficinas do PETFIS, percebe-se um evidente distanciamento da média de notas na OBA, de acordo com a Figura 3.

Figura 3: Indicação da nota média dos alunos participantes da OBA com separação entre alunos que participaram e não participaram das oficinas do PETFIS, no período de 2014 a 2019.

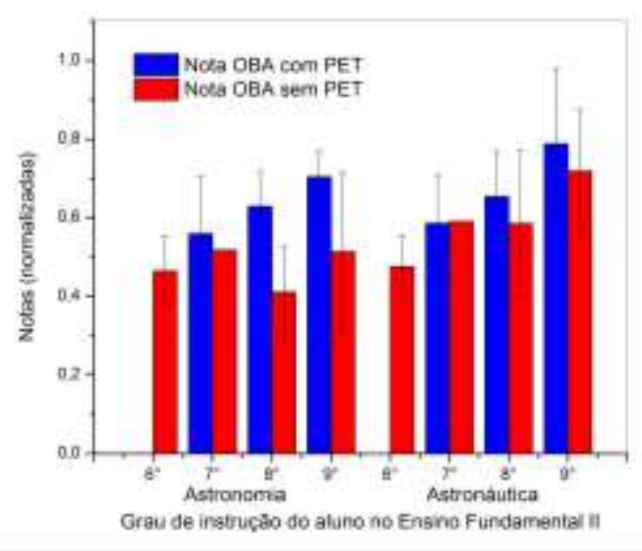

Fonte: Autores. 
Fica, mais uma vez, clara a participação positiva do grupo PETFIS quanto ao desempenho dos alunos. Em vermelho, são apresentadas as notas do grupo de alunos que participaram da OBA sem participar das oficinas e, em azul, as notas do grupo de alunos que participaram da OBA e das oficinas, em todos os anos do Ensino Fundamental. Este resultado mostra que a intervenção do grupo PET por meio das oficinas e atividades extracurriculares fomentou maior eficiência na execução das avaliações.

Uma nova análise a respeito do desempenho dos alunos na escola foi feita comparando-se a nota média obtida por eles e a relação de medalhas por participantes. Assim, a Figura 4 traz esses dados para os alunos do $7^{\circ}$ ao $9^{\circ}$ ano do Ensino Fundamental que participaram da OBA.

Figura 4: Indicação da nota média dos alunos participantes da OBA e relação de medalhas por participante no período de 2014 a 2019

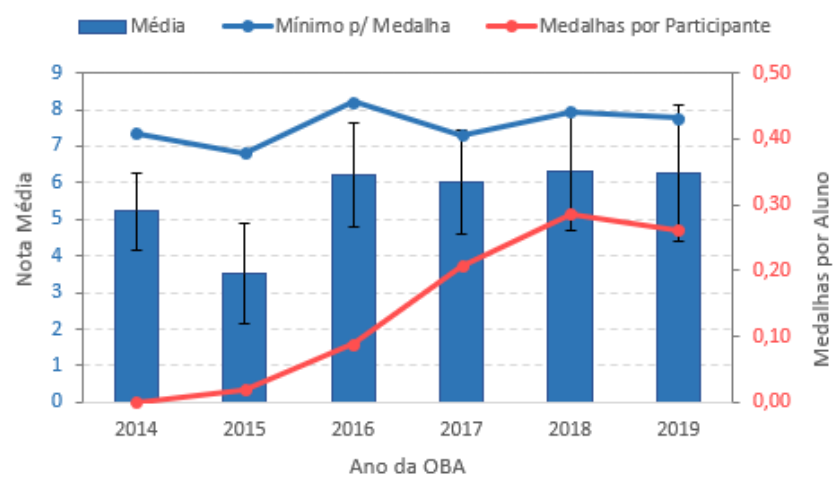

Fonte: Autores.

A análise da Figura 4 deixa clara a evolução da escola quanto ao seu desempenho na OBA a partir do ano de 2016, momento em que se registra maior nota média dos alunos. Nos anos seguintes, essas notas se mantêm praticamente constantes. Observa-se ainda um grande aumento no número de medalhas obtidas por aluno, passando de 1 medalha para cada 50 alunos em 2015 para aproximadamente 1 medalha para cada 4 alunos, nos anos de 2018 e 2019. É claro que esse número depende do grau de dificuldade da avaliação, mas esse índice de nota de corte, ou nota mínima para alcançar a medalha, é feito considerando-se a média nacional das notas obtidas por todos os participantes.

A partir da interpretação dos dados qualitativos, verificou-se que todas as partes foram positivamente afetadas, o que se mostrou evidente pelos relatos dos envolvidos. Sob o ponto de vista da Professora de Ciências que trabalha na escola onde o projeto foi aplicado, o relato foi o seguinte:

Esse grupo de alunos da Unifei, que desenvolve um projeto de apoio ao ensino de Física e conceitos de Astronomia, se destaca devido aos seguintes fatores: 1) Planejam o conteúdo de acordo com as necessidades dos nossos alunos. 2) Fazem o agendamento das aulas e cumprem com responsabilidade e pontualidade. 3) Quando convidados para algum evento na escola demonstram disponibilidade e prazer em participar. 4) Desde que envolveram com a nossa escola, sensibilizaram os nossos alunos a participarem da Olimpíada Brasileira de Astronomia e temos conseguido bons resultados. 5) O professor-orientador do grupo é um grande facilitador. 6) E, preciso falar do sentimento de respeito e carinho existente entre a escola e o grupo. 
Do ponto de vista dos Petianos, o trabalho com o PETFIS é uma das melhores experiências que ocorreu durante a graduação, pois proporcionou a eles o desenvolvimento de várias habilidades como trabalho em equipe, promoção de liderança, didática, oratória, desinibição, entre várias outras, além de aguçar um comportamento humanitário e cooperativo.

Eles também se encantam que o trabalho realizado causou fascínio e puderam quebrar barreiras principalmente no campo da comunicação, quando a curiosidade superou o medo da interação social com pseudodesconhecidos.

As Falas da Docente e dos Petianos deixaram clara a satisfação na execução das atividades. Isso indica que o PET segue uma metodologia inclusiva, uma vez que verifica a necessidade dos alunos e promove as atividades preparadas especialmente para o grupo. E que de forma qualitativa também é observada, pelos próprios Petianos, a aquisição de habilidades favoráveis ao melhor empenho acadêmico e social.

\section{Considerações Finais}

A Astronomia faz parte da cultura do homem desde a pré-história e vem, ao longo dos anos, sendo estudada com o objetivo de expandir o conhecimento humano sobre o universo e toda a sua imensidão. Contudo, uma grande dificuldade no aprendizado relacionado a este tema se instaurou nas escolas. O PETFIS trouxe uma abordagem diferente de ensino para que os estudantes compreendessem a importância de estudar os astros, o sistema solar e tudo que abrange a Astronomia em si, construindo o conhecimento científico por um processo de ensino-aprendizagem de forma lúdica e aguçando o interesse dos alunos sobre os conceitos astronômicos. Considerando este contexto e o fato de Itabira ter sido por muitos anos uma cultura baseada no extrativismo mineral, os resultados mostram como é importante a interação do homem com métodos científicos e que estes podem fornecer informações de forma leve e intuitiva.

Certamente, isso tem um potencial promissor aos que entram em contato com as abordagens técnicas, a capacidade de participar de competições e de tratar desses assuntos, que a princípio são vistos como complicados, com naturalidade e com um olhar no prático repleto de contextualização teórica impulsionando-os a querer ir cada vez mais longe. Além disso, o efeito de promover cultura na sociedade é fundamental para sua ascensão.

Essa afirmação pode ser feita, sem anseio, uma vez que foi observada uma melhora significativa nas notas dos alunos participantes da OBA, certificada por premiações cada vez mais numerosas. E ainda, assentida pelos depoimentos dos participantes que dissertaram sobre a participação interativa dos alunos durante o treinamento.

O Grupo PET Conexão de Saberes em Física e Popularização da Ciência e a professora de Ciências realizaram um trabalho de excelência promovendo um ensino diferenciado na Escola. Dessa forma, reforça-se a importância do grupo PETFIS e de suas ações na escola para a formação e preparação dos alunos para participar de competições e obter melhor desempenho. Atualmente, o grupo vem utilizando ferramentas virtuais de ensino, como vídeos animados e jogos na forma de quiz. Espera-se que essa constante interação contribua com a formação dos alunos, bem como com o crescente desempenho dos alunos.

\section{Agradecimentos}

Os autores agradecem ao Programa de Educação Tutorial/MEC pelo suporte financeiro, a todos os alunos envolvidos no projeto ao longo dos anos e a direção do Colégio Municipal Professora Didi Andrade da cidade de Itabira, MG, pelo apoio ao projeto.

\section{Referências}

Arantes, A. R. V., \& Barbosa, J. T. S. (2017). O lúdico na educação infantil. Revista Online de Magistro de Filosofia, Ano X(21), 100-115. 
Bassalo, J. M. F., \& Cattani, M. (2018). O prêmio Nobel de Física de 2017 e as instituições brasileiras de pesquisas físicas. Caderno Brasileiro de Ensino de Física, 35(2), 440-460. https://doi.org/10.5007/2175-7941.2018v35n2p440

Bertolami, O. (2016). Do Big Bang ao Homem. In H. Couto \& O. Bertolami (Eds.), O Big Bang: a origem do universo (pp. 1-11). Porto: Editora da Universidade do Porto.

Canalle, J. B. G., Neto, E. R., Nascimento, J. O. do, Klafke, J. C., Caraviello, T. P., Rojas, G. de A., \& Diaz, M. (2015). Resultados da XVIII Olimpíada Brasileira de Astronomia e Astronáutica. http://www.oba.org.br/sisglob/sisglob_arquivos/Relatorio da XVIII OBA - 2015.pdf

Canalle, J. B. G., Rocha, J. F. V. da, Souza, C. A. W. de, Ortiz, R. P., Aguilera, N. V., Padilha, M. de F. C. P., Rodrigues, I. M. S. (2010). Resultados da XIII Olimpíada Brasileira de Astronomia e Astronáutica. http://www.oba.org.br/sisglob/sisglob_arquivos/historico_da_oba/Relatorio_da_XIII_OBA.pdf, 2010

Canalle, J.B.G., Trevisan, R., \& Lattari, C. (1997). Análise do conteúdo de astronomia de livros de geografia de $1^{\circ}$ grau. Caderno Brasileiro de Ensino de Física, 14(3), 254-263. https://doi.org/10.5007/\%x

Celletti, A., \& Perozzi, E. (2007). Around and around. In A. Celletti \& E. Perozzi (Eds.), Celestial Mechanics (pp. 1-23). Springer Praxis Books. Retrieved from http://link.springer.com/10.1007/978-0-387-68577-9_1

Costa Junior, E., Fernandes, B. da S., Lima, G. da S., Siqueira, A. de J., Paiva, J. N. M., Santos, M. G. \& Gomes, T. M. F. (2018). Divulgacão e ensino de Astronomia e Física por meio de abordagens informais. Revista Brasileira de Ensino de Física, 40(4), 1-8. https://doi.org/10.1590/1806-9126-rbef-2018-0051

Dubet, F. (2004). O que é uma escola justa? Cadernos de Pesquisa, 34(123), 539-555. https://doi.org/10.1590/s0100-15742004000300002

Erthal, J. P. C., \& Vieira, A. D. S. (2019). Vinte anos de OBA: uma análise da evolução do exame ao longo dos anos. Revista Latino-Americana de Educação Em Astronomia, (27), 35. https://doi.org/10.37156/RELEA/2019.27.035

Felicetti, S. A., Miorando, I. C., \& Ohse, M. L. (2017). Aprendizagem de conceitos de astronomia no ensino fundamental: uma oficina didática em preparação para a OBA. Góndola, Enseñanza y Aprendizaje de Las Ciencias, 12(2), 32. https://doi.org/10.14483/23464712.10035

Germano, M. G., \& Kulesza, W. A. (2007). Popularização da ciência: uma revisão conceitual. Caderno Brasileiro de Ensino de Física, 24(1), 7-25.

Langhi, R., \& Nardi, R. (2005). Dificuldades de professores dos anos iniciais do ensino fundamental em relação ao ensino da Astronomia. Revista LatinoAmericana de Educação Em Astronomia, (2), 75-91. https://doi.org/10.37156/RELEA/2005.02.075

Langhi, R., \& Nardi, R. (2007). Ensino de Astronomia: Erros conceituais mais comuns presente em livros didáticos de ciência. Caderno Brasileiro de Ensino de Física, 24(1), 87-111. https://doi.org/10.5007/6055

Langhi, R., \& Nardi, R. (2009). Ensino da astronomia no Brasil: educação formal, informal, não formal e divulgação científica. Revista Brasileira de Ensino de Fisica, 31(4). https://doi.org/10.1590/s1806-11172009000400014

Lavouras, D. F. (1998). Relatório da I Olimpíada Brasileira de Astronomia. Retrieved from http://www.oba.org.br/sisglob/sisglob_arquivos/Nascimento da OBA.pdf

Leite, C., \& Hosoume, Y. (2007). Os professores de ciências e suas formas depensar a Astronomia. Revista Latino-Americana de Educação Em Astronomia, 4, $47-68$.

Marandino, M., Silveira, R. V. M. Da, Chelini, M. J., Fernandes, A. B., Martins, L. C., Florentino, H. A., \& Universidade, A. (2004). A Educação não formal e a divulgação científica: o que pensa quem faz? In Encontro Nacional de Pesquisa em Ensino de Ciências (pp. 1-13). Bauru: Atas do IV ENPEC. Bauru: Unesp.

Miranda, J. C., Gonzaga, G. R., Costa, R. C., Freitas, C. C. C., \& Côrtes, K. C. (2016). Jogos didáticos para o ensino de Astronomia no ensino fundamental. Scientia Plena, 12(2), 1-10. https://doi.org/0.14808/sci.plena.2016.020701

Morais, E. A. de, Pedro, D. F. P., Fernandes, B. M., Silva, J. J. R., Cruz, M. P., Nogueira Neto, L. F., \& Geraldo, V. (2020). Curso Popular Preparatório para o Exame Nacional do Ensino Médio: um meio de Inclusão Social em Itabira. Research, Society and Development, 9(5), e60952849. https://doi.org/10.33448/rsdv9i5.2849

Neves, M. C. D. (1986). Astronomia de régua e compasso: de Kepler a Ptolomeu. Unicamp. http://repositorio.unicamp.br/jspui/handle/REP OSIP/277377\%0AFacebookTwitter

Oliveira Filho, K. O., \& Saraiva, M. de F. atima O. (2013). Astronomia e Astrofísica (3a ed.). Livraria da Fisica.

Paula, A. L., \& Sanzovo, D. T. (2018). Ensino de Astronomia: uma aplicação do AstroRummikub no ensino fundamental. Educação Pública. https://educacaopublica.cecierj.edu.br/artigos/18/17/ensino-de-astronomia-uma-aplicao-do-astrorummikub-no-ensino-fundamental

Pereira, A. S., Shitsuka, D. M., Parreira, F. J., \& Shitsuka, R. (2018). Metodologia da pesquisa científica UFSM. https://repositorio.ufsm.br/bitstream/handle/1/15824/Lic_Computacao_Metodologia-\%0APesquisa-Cientifica.pdf?sequence=1.

Pliessing, A. F., \& Menta, E. (2008). E o tempo passa... - Parte 1 / Dia e Noite. http://portaldoprofessor.mec.gov.br/fichaTecnicaAula.html?aula=1352

Ramos, M. P., \& Maluf, R. V. (2018). Sobre a teoria de Einstein para ondas gravitacionais e sua aplicacão no estudo da radiacão emitida por um pulsar binário. Revista Brasileira de Ensino de Fisica, 40(2). https://doi.org/10.1590/1806-9126-RBEF-2017-0177

Rezende, F., \& Ostermann, F. (2012). Olimpíadas de ciências: uma prática em questão. Ciência \& Educação (Bauru), 18(1), 245-256. https://doi.org/10.1590/s1516-73132012000100015

Rodrigues, F. M., \& Briccia, V. (2016). O ensino de Astronomia e a alfabetização científia nos anos iniciais: relações possíveis. In: IV Simpósio Nacional de 
Research, Society and Development, v. 10, n. 10, e158101018608, 2021

(CC BY 4.0) | ISSN 2525-3409 | DOI: http://dx.doi.org/10.33448/rsd-v10i10.18608

Educação em Astronomia (pp. 1-10). atas do IV SNEA.Goiânia: UFG

Sagan, C. (1980). Cosmos (1a ed.). Random House.

Sagan, C., \& Druyan, A. (1980). Cosmos: uma viagem pessoal. Carl Sagan Productions, KCET, BBC e Polytel International.

Schwarza. (2018). Do átomo ao buraco negro: o universo em escala. Outro Planeta.

Souza, M. A. B. de, Gualberto, D. A., Nogueira Neto, L. F., Soares, J. D. A., Fernandes, B. M., \& Morais, E. A. de. (2021). Contribuições dos experimentos de Física em feiras e planetário itinerantes na desmistificação do aprendizado: Um estudo de caso de um grupo de educação tutorial na Unifei. Research, Society and Development, 10(7), e50010716859. https://doi.org/10.33448/rsd-v10i7.16859

Souza, L. N. M. (2019). Entre a vila e a mina: violações de direitos em Itabira. (Dissertação de mestrado, Universidade Federal de Minas Gerais, Belo Horizonte, Brasil). Retrieved from https://repositorio.ufmg.br/bitstream/1843/31842/1/Lucas Nasser \%28Dissertação\%29.pdf

Unifei/História. (2018). https://unifei.edu.br/institucional/historia/ 